\title{
Is single reading with computer-aided detection (CAD) as good as double reading in mammography screening? A systematic review
}

\author{
Edward Azavedo ${ }^{1,4}$, Sophia Zackrisson ${ }^{2 *}$, Ingegerd Mejàre ${ }^{3}$ and Marianne Heibert Arnlind ${ }^{3,4}$
}

\begin{abstract}
Background: In accordance with European guidelines, mammography screening comprises independent readings by two breast radiologists (double reading). CAD (computer-aided detection) has been suggested to complement or replace one of the two readers (single reading $+C A D$ ).

The aim of this systematic review is to address the following question: Is the reading of mammographic x-ray images by a single breast radiologist together with CAD at least as accurate as double reading?

Methods: The electronic literature search included the databases Pub Med, EMBASE and The Cochrane Library. Two independent reviewers assessed abstracts and full-text articles.

Results: 1049 abstracts were identified, of which 996 were excluded with reference to inclusion and exclusion criteria; 53 full-text articles were assessed for eligibility. Finally, four articles were included in the qualitative analysis, and one in a GRADE synthesis.

Conclusions: The scientific evidence is insufficient to determine whether the accuracy of single reading + CAD is at least equivalent to that obtained in standard practice, i.e. double reading where two breast radiologists independently read the mammographic images.
\end{abstract}

Keywords : CAD, Mammography, Screening, Breast, Cancer, Single reading, Double reading

\section{Background}

Following reports from Swedish randomized trials [1-4], breast cancer screening programs with mammography have been established in recent decades in many countries [5]. The age range of women invited to screening varies between countries. The Swedish National Board of Health and Welfare recommends mammography screening at regular intervals to all women between 40 and 74 years. The initial results from the randomized trials, showing a reduction in mortality in breast cancer, have been confirmed by long-term follow-up [6,7] Similar results have been obtained in established populationbased service screening programs $[8,9]$. However, the pros and cons of mammography screening and how the

\footnotetext{
* Correspondence: sophia.zackrisson@med.lu.se

2Department of Clinical Sciences in Malmö, Diagnostic Radiology, Lund University, Skåne University Hospital Malmö, Malmö SE-205 02, Sweden Full list of author information is available at the end of the article
}

results should be interpreted [10] are still matters for debate.

Besides the primary aim of detecting breast cancers in screening programs, it is important that recall rates are kept as low as possible without impairing detection rates. In this respect, the recommended recall rate in Sweden and in the rest of Europe should not exceed five per cent [11]. The reasons for recall are several, such as suspicious findings suggesting malignancy, indeterminate findings that need further work-up, and occasionally for technical reasons or if the woman reports clinical symptoms at the time of the screening examination.

As the radiological image of breast tissue is complex, mammograms need to be interpreted by highly specialized radiologists. Figure 1 shows an example of mammography images.

Factors that affect the ability to detect a breast cancer (sensitivity) are e.g. the prevalence of breast cancer in the target population, dense breast tissue, the frequency

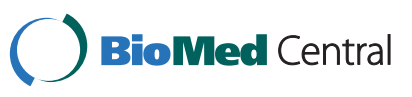



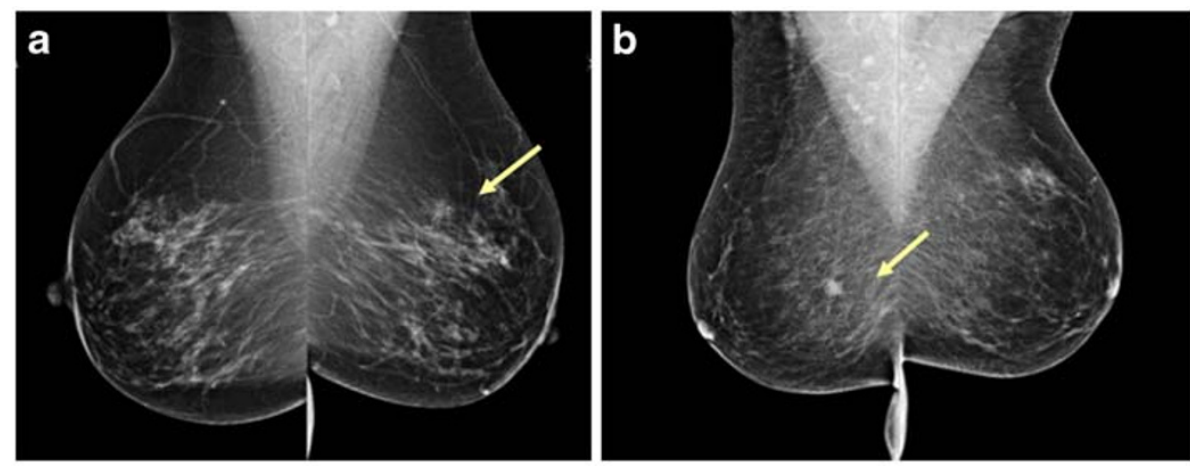

Figure 1 Figure 1a shows a rather hard to detect breast cancer in the left breast (arrow); the right breast is normal. Figure $1 \mathrm{~b}$ shows an easily detected cancer in the right breast (arrow); the left breast is normal.

of tumours with subtle mammographic signs, and suboptimal technical quality. These factors, combined with high daily volumes (each Swedish screening centre usually screens more than 20,000 women annually), makes accurate screening a challenging task. Sensitivity levels of $70-85 \%$ and specificity levels of $82-98 \%$ at mammography screening have been reported [5]. In order to maintain high sensitivity and specificity, resulting in high cancer detection rates and low false-positive rates, Swedish and European guidelines recommend double reading, i.e. that the breast images are reviewed by two specially trained radiologists (breast radiologists). Double reading has been shown to increase cancer detection rates by 5-17\% [12].

Computer-aided detection (CAD) is a computerized method for analysing images in mammography screening. Although the method has existed for approximately 10 years, its contribution to routine screening is still debatable [13-15]. The program used in CAD identifies and marks areas which the software identifies as abnormal breast tissue. The CAD program is not intended to be the sole method for analysing mammography images. Rather, it is designed to alert the radiologist to possibly suspicious areas. Hence, a radiologist must interpret and make a decision to act upon (accept or dismiss) each CAD mark. On average, each screening examination generates two false positive marks; CAD gives 400 false positive marks for each true positive mark [16].

Lack of an adequate number of trained breast radiologists has led to a growing interest in computerized analysis of mammography images. There has been a discussion as to whether CAD in conjunction with mammography screening could replace one of the breast radiologists. A prerequisite would be that diagnostic accuracy and patient benefit are at least equivalent to what is achieved when the mammographic images are read by two breast radiologists. Another important prerequisite is that not too many women need to be recalled for further diagnostic work-up.
The value of CAD in mammography screening has been questioned in earlier reviews $[17,18]$. The literature is scarce on studies performed in authentic screening situations. As the performance of CAD systems has improved considerably, it was considered appropriate to reassess the performance of $\mathrm{CAD}$ in population-based screening programs.

This review is part of a comprehensive systematic review, published in Swedish by SBU (Swedish Council on Health Technology Assessment), of computer-aided detection (CAD) as a diagnostic method in mammography screening [19]. SBU is an independent government agency for the critical evaluation of methods for preventing, diagnosing and treating health problems.

The objective of the present is systematic review is to address the following question: Is the reading of mammographic images by a single breast radiologist plus $\mathrm{CAD}$ at least as accurate as readings by two breast radiologists (current practice) in terms of:

- sensitivity (probability that a person with the disease has a positive test result);

- specificity (probability that a healthy person has a negative test result);

- cancer detection rate (number of cancer cases detected per 1,000 women examined);

- recall rate (proportion of women who are recalled for further investigation); and

- cost-effectiveness?

\section{Methods}

\section{CAD (Computer-aided detection)}

CAD research has been developed over the past two decades. CAD was first applied to digitized (scanned) screen-film mammograms (SFM). The introduction of full-field digital mammography (FFDM) has led to intensified efforts to optimise the method. CAD makes a computerized analysis of mammograms and identifies areas that need to be reviewed. The precise algorithms 
used by different CAD suppliers are still a commercial secret and are not further reviewed here. Two types of marks are generally used: one for microcalcifications and the other for other mammographic features such as density, mass and distortion. The systems can be adjusted to yield very high sensitivity but at the cost of specificity, generating a high rate of false positive marks.

According to a recent review, the sensitivity of CAD for microcalcifications representing malignancies is $98-$ $99 \%$ [16]. However, only $15-20 \%$ of detected cancers present as microcalcifications on screening mammograms [20]. The same review reports that the sensitivity of CAD for other mammographic features representing malignancies ranges from 89 to $75 \%$, in some cases down to $50 \%$.

It has been assumed that CAD will be used increasingly with the transition from analogue to digital mammography. The reproducibility of CAD prompts in FFDM is expected to be more consistent than with scanned mammograms. The primary inclusion criterion in this review was CAD on FFDMs. However, when prospective studies based on FFDM could not be found, scanned analogue images were accepted.

\section{Literature search and selection of articles}

The electronic literature search included the databases PubMed, EMBASE, and The Cochrane Library from 1950 to November 2011. All Western European languages were accepted. The Mesh terms were: Breast neoplasms, Breast, Mammography, Breast (TW), Mammography (TW) AND Computer aided detection (TW) AND Computer aided diagnosis (TW) AND Cad (TW), and Economic aspects. The complete search strategy can be provided on request.

The electronic searches yielded 1049 abstracts (Figure 2). Two reviewers (EA and SZ) read the abstracts independently. An article was read in full text if at least one of the two reviewers considered an abstract to be potentially relevant. Hand search and grey literature did not result in any additional articles. The

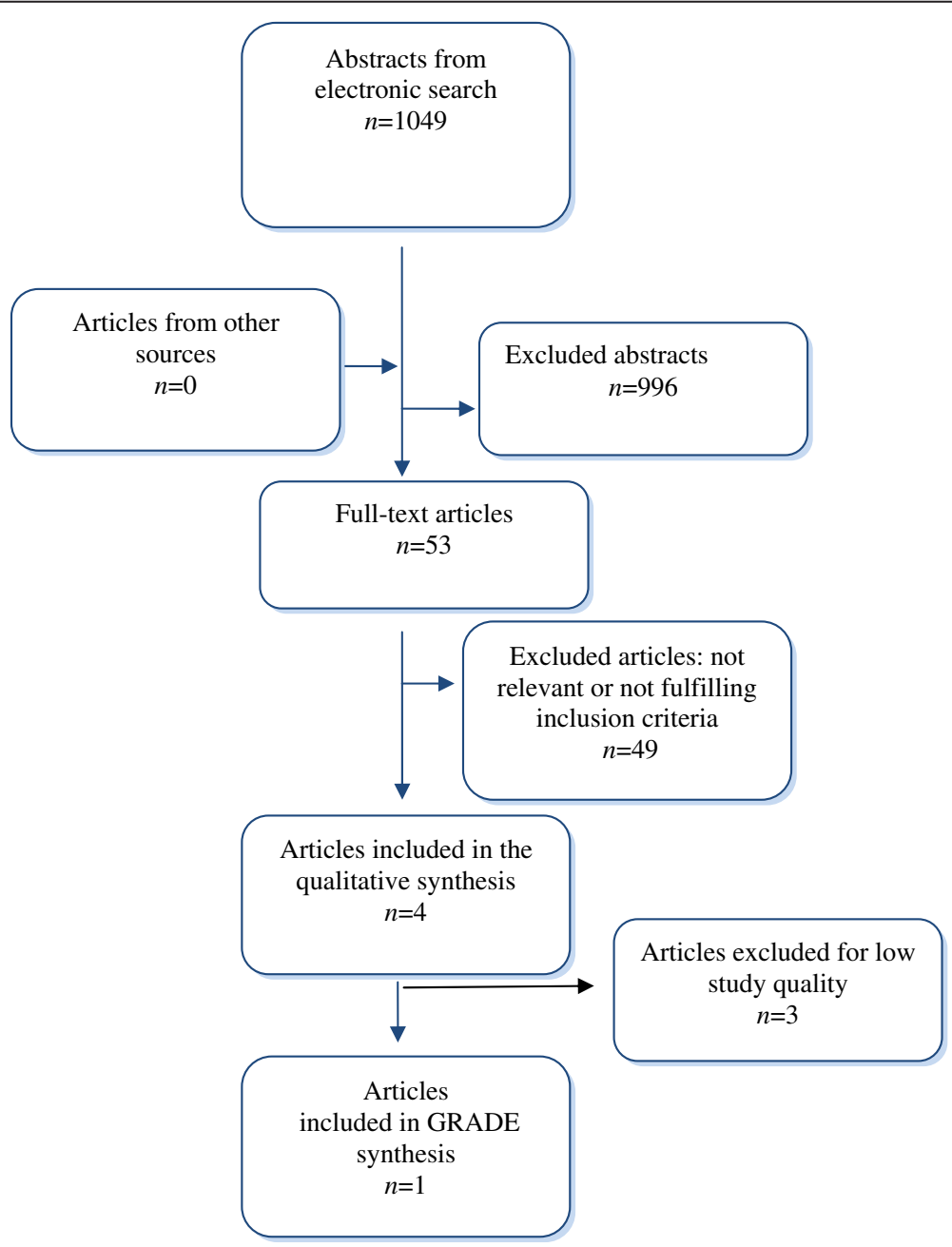

Figure 2 Flow chart of the search strategy. 
pre-specified inclusion/exclusion criteria are given below. Altogether, 53 articles were read in full text and assessed independently by the same two reviewers using the QUADAS tool [21]. Of the 53 articles, 49 did not fulfil the inclusion criteria and were excluded from further analysis. A list of excluded articles with the main reason for exclusion is available on request.

PICO elements were used to describe the population, index test, reference test and outcome:

P - Population: women, 40-74 years old, participating in mammography screening

I - Intervention (index test): CAD + one breast

radiologist (single reading)

$\mathrm{C}$ - Control (reference test): reading by two independent radiologists (double reading)

$\mathrm{O}$ - Outcome: sensitivity, specificity, cancer detection

rate and recall rate

The inclusion criteria were:

- population-based screening

- $\geq 5,000$ women included

- study setting corresponding to Swedish conditions

- follow-up time $\geq 12$ months

- mammography readings with one breast radiologist + CAD compared with readings by two breast radiologists.

\section{Assessment of diagnostic accuracy}

The diagnostic accuracy (validity) of a test (index test) requires a reference standard (reference test) for comparison. Two index tests were used here: 1) CAD + single reading, and 2) double reading. The reference standard should reflect the reality as closely as possible and the ideal gold standard is histopathological verification. However, biopsying all individuals is not feasible when screening an asymptomatic population. The reference standard in this review was biopsy of suspected cases or follow-up. The ultimate outcome was survival. Because no randomized controlled trials have been performed to document changes in survival following the use of double reading compared to single reading with CAD, surrogate outcomes such as cancer detection rate and recall rate are used. The main outcome measures are sensitivity and specificity. Sensitivity is the number of true positive tests divided by the total number of true cancer cases. Specificity is the number of true negative tests divided by the total number of healthy breast cases. In addition, cost-effectiveness has been considered.

\section{Rating quality of individual studies}

The quality of each included study was rated high, moderate or low according to pre-specified criteria given in Table 1.

\section{Rating evidence across studies}

The quality of the evidence of each method's/test's diagnostic accuracy was rated in four levels according to GRADE [22] [23]:

- High $(\oplus \oplus \oplus \oplus)$. Based on high or moderate quality studies containing no factors that weaken the overall judgement.

- Moderate $(\oplus \oplus \oplus \mathrm{O})$. Based on high or moderate quality studies containing isolated factors that weaken the overall judgement.

- Limited $(\oplus \oplus \mathrm{OO})$. Based on high or moderate quality studies containing factors that weaken the overall judgement.

- Insufficient $(\oplus \mathrm{OOO})$. The evidence base is insufficient when scientific evidence is lacking, the quality of available studies is low or studies of similar quality are contradictory.

Table 1 Criteria of high, moderate and low study quality, mainly according to QUADAS [21]

\begin{tabular}{ll}
\hline High: small risk of bias & Prospective study design. Particular emphasis on the following: \\
- adequately described patients constituting a representative and clinically relevant \\
sample (QUADAS items 1, 2). \\
- the index test should not form part of the reference standard (item 7). \\
- evaluators should be masked to results of index test and reference test (items 10, 11) \\
- the tests should be described in sufficient detail to permit replication (items 8, 9). \\
- sample size $\geq 5000$. \\
- diagnostic accuracy presented as sensitivity and specificity. \\
Moderate: moderate risk of bias & Prospective study design \\
& Since no prospective studies based on digital mammography could be identified, \\
& scanned analogue images were accepted. Otherwise the same criteria as for \\
Low: high risk of selection and/or verification bias & Retrospective study design. Selected or enriched samples
\end{tabular}




\begin{tabular}{|c|c|c|c|c|c|}
\hline Author, Year (ref) & $\begin{array}{l}\text { Study design, Study period, } \\
\text { Population, Readers }\end{array}$ & Index test (I) & Reference test & $\begin{array}{l}\text { Results } \\
\mathrm{Cl}=\text { confidence interval } \\
\mathrm{Se}=\text { sensitivity } \\
\mathrm{Sp}=\text { specificity }\end{array}$ & Study quality, Comments \\
\hline \multirow[t]{19}{*}{ Gilbert et al., 2008 [71] } & \multirow{2}{*}{$\begin{array}{l}\text { Prospective, } \\
\text { multicentre 2006-2007 }\end{array}$} & \multirow{3}{*}{$\begin{array}{l}\text { I.1: single reading }+C A D \text {, } \\
n=28,204\end{array}$} & \multirow{19}{*}{$\begin{array}{l}\text { Biopsy of suspected } \\
\text { cases or follow-up } \\
\text { (not all, though; number } \\
\text { not reported) }\end{array}$} & Cancer detection rate: & \multirow[t]{2}{*}{ Moderate } \\
\hline & & & & Single reading + CAD: 7.02 /1000 & \\
\hline & Population: & & & Double reading: 7.06/1000. & Restricted generalisability since \\
\hline & Initially invited: 68,060 women. & \multirow[t]{16}{*}{$\begin{array}{l}\text { I.2: double reading, } \\
\mathrm{n}=28,204 \text {. }\end{array}$} & & $\begin{array}{l}\text { Difference not statistically } \\
\text { significant (NS). }\end{array}$ & $\begin{array}{l}\text { results were based on } \\
\text { single reading }+C A D \\
\text { by experienced radiologists. }\end{array}$ \\
\hline & Investigated: 28,204. & & & Recall rate: & \multirow{2}{*}{$\begin{array}{l}\text { Incomplete follow-up, } \\
\text { particularly affecting } \\
\text { the estimates } \\
\text { of sensitivity. }\end{array}$} \\
\hline & \multirow[t]{2}{*}{$\begin{array}{l}\text { Aged } 50-70 \text { years } \\
\text { ( } 1 \%>70 \text { years). }\end{array}$} & & & Single reading + CAD: $3.9 \%$ & \\
\hline & & & & Double reading: $3.4 \%$. & \multirow{13}{*}{$\begin{array}{l}\text { Scanned analogue } \\
\text { mammograms. }\end{array}$} \\
\hline & \multirow{5}{*}{$\begin{array}{l}\text { Readers: radiologists }(n=17) \\
\text { specially trained staff }(n=10)\end{array}$} & & & Difference 0.5 \% (95 \% Cl: 0.3;0.8). & \\
\hline & & & & Accuracy: & \\
\hline & & & & Single reading $+C A D$ : & \\
\hline & & & & $\mathrm{Se}=87.2 \%$ & \\
\hline & & & & $S p=96.9 \%$ & \\
\hline & \multirow{7}{*}{$\begin{array}{l}\text { All readers had at least } 6 \text { years' } \\
\text { experience and }>5000 \text { readings/year }\end{array}$} & & & Double reading: & \\
\hline & & & & $\mathrm{Se}=87.7 \%$ & \\
\hline & & & & $S p=97.4 \%$ & \\
\hline & & & & Difference in sensitivity: & \\
\hline & & & & $0.5 \%$ (95 \% Cl: & \\
\hline & & & & $-7.4 ; 6.6),(N S)$ & \\
\hline & & & & $\begin{array}{l}\text { Difference in specificity } 0,5 \% \\
\text { ( } \mathrm{Cl} \text { not specified but reported NS). }\end{array}$ & \\
\hline \multirow[t]{7}{*}{ Gromet et al., 2008 [69] } & Retrospective & \multirow[t]{3}{*}{ I.1: Single reading + CAD } & \multirow[t]{7}{*}{ Biopsy and follow-up } & Cancer detection rate: & Low \\
\hline & Population: & & & Single reading + CAD: 4.2/1000. & \multirow{3}{*}{$\begin{array}{l}\text { Retrospective study } \\
\text { (controlled for age and time } \\
\text { since last screening). }\end{array}$} \\
\hline & 231221 women & & & Double reading: 4.46/1000 (NS). & \\
\hline & 2001-05 & $n=118,808$ & & & \\
\hline & Readers: & I.2: Double reading & & & Follow-up time unclear. \\
\hline & \multirow{2}{*}{$\begin{array}{l}\text { Single reading + CAD: } \\
\text { specialists in mammography. }\end{array}$} & \multirow[t]{2}{*}{$n=112,413$} & & Recall rate: & \multirow{2}{*}{$\begin{array}{l}\text { Screening situation } \\
\text { not applicable } \\
\text { to European conditions }\end{array}$} \\
\hline & & & & Single reading + CAD: $10.6 \%$ & \\
\hline
\end{tabular}


Table 2 Main characteristics, results and quality rating of four studies on mammography screening (Continued)

\begin{tabular}{|c|c|c|c|c|c|}
\hline & \multirow{11}{*}{$\begin{array}{l}\text { Double reading: } \\
\text { Specialists in mammography + radiology. }\end{array}$} & & & Double reading:11.9\%. & \multirow{4}{*}{$\begin{array}{l}\text { (i.e. recall rate higher than } \\
\text { accepted in Europe). } \\
\text { Invitation procedure } \\
\text { and blinded readings unclear. }\end{array}$} \\
\hline & & & & \multirow{3}{*}{$\begin{array}{l}\text { Difference statistically } \\
\text { significant }(p=0.001) \text {. } \\
\text { Accuracy: }\end{array}$} & \\
\hline & & & & & \\
\hline & & & & & \\
\hline & & & & Single reading $+\mathrm{CAD}: \mathrm{Se}=90.4 \%$ & Scanned analogue \\
\hline & & & & Double reading: & mammograms. \\
\hline & & & & $\mathrm{Se}=88.0 \%$ & \\
\hline & & & & Difference statistically significant. & \\
\hline & & & & Percent of recalled with cancer: & \\
\hline & & & & Single reading + CAD: $3.9 \%$. & \\
\hline & & & & Double reading: 3.7\%(NS). & \\
\hline \multirow[t]{11}{*}{ Georgian-Smith et al., 2007 [68] } & Prospective & I.1: Single reading + CAD & \multirow{11}{*}{$\begin{array}{l}\text { Biopsy and at least } \\
12 \text { months' follow-up to } \\
\text { detect false negatives. }\end{array}$} & Cancer detection rate: & Low \\
\hline & Study period: 2001-03 & & & Single reading +CAD: 2.0/1000. & \multirow{3}{*}{$\begin{array}{l}\text { Screening situation } \\
\text { not applicable to } \\
\text { European conditions. } \\
\text { Invitation procedure } \\
\text { not described. }\end{array}$} \\
\hline & \multirow{4}{*}{$\begin{array}{l}\text { Population: } 6381 \text { consecutive } \\
\text { screening examinations }\end{array}$} & $n=6381$ & & \multirow[t]{2}{*}{ Double reading: 2.4/1000 (NS). } & \\
\hline & & I.2: Double reading & & & \\
\hline & & & & Recall rate: & Population, selection criteria, \\
\hline & & \multirow[t]{6}{*}{$n=6381}$. & & Single reading +CAD: $7.87 \%$. & withdrawals unclear. \\
\hline & Readers: & & & Double reading: 7.93\% (NS). & Not independent double \\
\hline & \multirow[t]{2}{*}{ Experienced breast radiologists } & & & Accuracy: & reading but blinded to CAD \\
\hline & & & & \multirow[t]{3}{*}{$\begin{array}{l}\text { Sensitivity and specificity } \\
\text { not reported. }\end{array}$} & $\begin{array}{l}\text { Number of recalls } \\
\text { based on all readings. }\end{array}$ \\
\hline & Single reading + CAD. & & & & Scanned analogue radiographs. \\
\hline & $\begin{array}{l}\text { Double reading: } \\
\text { Not independent reading. }\end{array}$ & & & & \\
\hline \multirow[t]{7}{*}{ Khoo et al., 2005 [70] } & Prospective & \multirow{3}{*}{$\begin{array}{l}\text { I.1: Single reading }+C A D \\
n=6111\end{array}$} & Biopsy & Cancer detection rate: & Low \\
\hline & Study period: not reported. & & Not reported & Total for double & A so-called relative sensitivity \\
\hline & \multirow{5}{*}{$\begin{array}{l}\text { Population: 6,111 women } \\
\text { (45-94 years), screening } \\
\text { every 3rd year }\end{array}$} & & No follow-up & symptomatic patients:10/1000. & not yet achieved. \\
\hline & & \multirow[t]{4}{*}{$\begin{array}{l}\text { 1.2: Double reading } \\
\mathrm{n}=6111\end{array}$} & & $\begin{array}{l}\text { Not reported individually } \\
\text { for the groups. }\end{array}$ & $\begin{array}{l}\text { Relatively high screening age } \\
\text { and long screening intervals. }\end{array}$ \\
\hline & & & & Recall rate: & \\
\hline & & & & Single reading + CAD: $6.1 \%$. & $\begin{array}{l}\text { Unclear whether the } \\
\text { readings were blinded. }\end{array}$ \\
\hline & & & & Double reading: $5.0 \%$. & Incomplete follow-up. \\
\hline
\end{tabular}

rospective

Population: 6381 consecutive

$\mathrm{n}=638$

1.2: Double reading

$n=6381$

Readers:

Single reading + CAD

Prospective

( 5 -94 years), screening

\author{
readings were blinded.
}


Table 2 Main characteristics, results and quality rating of four studies on mammography screening (Continued)

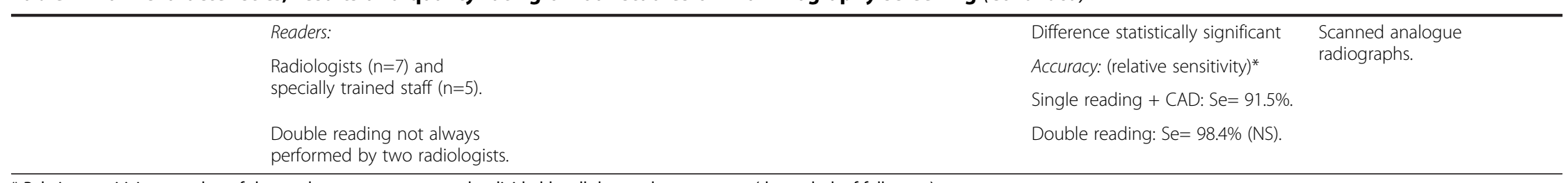

* Relative sensitivity= number of detected cancer cases per reader divided by all detected cancer cases (due to lack of follow-up).

Table 3 Quality of evidence of the difference between single reading (radiologist plus CAD) and double reading (two radiologists) related to cancer detection rate and recall rate in mammography screening (GRADE). Data from Gilbert et al. [71]

\begin{tabular}{|c|c|c|c|c|c|c|}
\hline Outcome & $\begin{array}{l}\text { Sample size } \\
\text { (no. of studies) }\end{array}$ & $\begin{array}{l}\text { True positive: } \\
\text { Single reading + CAD } \\
(95 \% \mathrm{Cl})\end{array}$ & $\begin{array}{l}\text { True positive: } \\
\text { Double reading } \\
(95 \% \mathrm{Cl})\end{array}$ & $\begin{array}{l}\text { Absolute difference } \\
(95 \% \mathrm{Cl})\end{array}$ & $\begin{array}{l}\text { Quality of } \\
\text { evidence }\end{array}$ & $\begin{array}{l}\text { Rating based on study } \\
\text { design/quality, indirectness, } \\
\text { consistency, precision and } \\
\text { publication bias** }\end{array}$ \\
\hline \multirow[t]{2}{*}{ Cancer detection rate } & $28,204(1)$ & $0.702 \%$ & $0.706 \%$ & $0.004 \%$ & $(\oplus \circ \bigcirc)$ & Study quality -1 \\
\hline & & $(0.6-0.8)$ & $(0.6-0.8)$ & $\left(N^{*}\right)$ & Insufficient & Indirectness-1 \\
\hline \multirow[t]{2}{*}{ Recall rate } & $28,204(1)$ & $3,9 \%$ & $3,4 \%$ & $0,5 \%$ & $(\oplus \mathrm{OOO})$ & Study quality -1 \\
\hline & & $(3,7-4,1)$ & $(3,2-3,6)$ & $(0,3-0,8)$ & Insufficient & Indirectness -1 One study -1 \\
\hline
\end{tabular}

*NS = no statistically significant difference.

** Study quality = Risk of bias, that is, sensitivity probably overestimated due to incomplete follow-up of women with negative test results.

Indirectness $=$ Only breast radiologists with long clinical experience took part in the study.

Lack of precision $=$ The difference in sensitivity between double reading and single reading + CAD has wide confidence intervals. 
Applying GRADE serves to obtain answers to the following questions. How much confidence can one have in a particular estimate of effect? Is the result sustainable, or is it likely that new research findings will change the evidence in the foreseeable future? The rating starts at high, but confidence in the evidence may be reduced for several reasons, including limitations in the study design and/or quality, inconsistency or indirectness of results, imprecise estimates and probability of publication bias. Any disagreements on inclusion/exclusion criteria, rating quality of individual studies or quality of evidence of test methods were solved by consensus.

- Sensitivity $=$ probability that a person with a disease has a positive test result.

- Specificity = probability that a healthy person has a negative test result.

- Relative sensitivity = number of detected cancer cases per reader divided by the total number of detected cancer cases.

- Population based mammography screening = all women in certain age groups receive a personal mailed invitation to get a mammogram at regular intervals $(1.5-3$ years $)$

- Cancer detection rate $=$ the number of cancer cases detected per 1000 women examined.

- Recall rate $=$ the number of women per 1000 woman recalled for further investigation.

- Interval cancer = cancer cases detected between two screening occasions.

\section{Results}

The results of the literature search and the outcome of the selection procedures are shown in a flow chart (Figure 2).

Fifty-three articles were reviewed in full text. Nine of them were review articles [12,16-18,24-28]. Many studies had not been performed in screening settings or had selected or enriched populations, sometimes without comparison between single reading $+\mathrm{CAD}$ and double reading [14,29-57]. Nine studies had large populations, but compared only single reading $+\mathrm{CAD}$ with single reading [58-66]. One study that only described different cancer types was excluded [67].

Four studies were included in the summary results, Table 2 (see Additional file 1). Three of them had methodological shortcomings and were judged to be of low quality [68-70]. Only one study, of moderate quality, was included in the GRADE synthesis, Table 3 [71]. This was a prospective multicentre study based on the UK national screening program and including 28,204 women aged 50-70 years. No statistically significant difference was found between single reading $+\mathrm{CAD}$ and double reading for cancer detection rate (7.02/1000 and 7.06/1
000). The overall agreement between the two strategies was $74.9 \%$ (170/227). However, single reading with CAD gave a significantly higher recall rate $(3.9 \%$ versus $3.4 \%$; $\mathrm{p}=0.001)$. Compared to double reading, single reading with CAD gave lower sensitivity (87.2\% versus $87.7 \%$ ) and lower specificity (96.9\% versus $97.4 \%$ ) but the differences were not statistically significant. Due to incomplete follow-up, sensitivity was likely to be overestimated. Overall, there was no statistically significant difference between the two strategies as regards pathological characteristics of the 57 detected cancers. Study results are reported in Tables 2 and 3.

Because of their shortcomings, the remaining three studies were not considered in our conclusions. However they deserve to be described. Two were conducted in the U.S.A. $[68,69]$, where population-based screening programs are not used. The populations are less well described and it is not clear whether the women received a personal invitation or had sought to get for mammography on their own. Moreover, recall rates were $8-12 \%$, notably higher than recommended in Sweden and Europe $(<5 \%)$. The larger of these two studies was retrospective and included 231,221 women who underwent mammography screening [69]. The other study was prospective with 6381 consecutive screening examinations [68]. Their results showed no statistically significant difference in cancer detection rate and the recall rates were inconsistent.

The third study was conducted within the framework of the United Kingdom National Health Service Screening Programme [70]. It was prospective and included 6111 screening examinations with a relatively high total cancer detection rate; 10/1000 including those detected by double reading and single reading with CAD and because of symptoms. Even women over 64 years of age (the upper limit for screening in the UK) were included, which may partly explain the relatively high prevalence of cancer cases. Another explanation may be that the interval between screening sessions was three years (usually 1.5-2 years in Europe). Due to lack of follow-up, the authors calculated a so-called relative sensitivity, where single reading + CAD gave a lower but not statistically significantly different sensitivity of $91.5 \%$ compared to $98.4 \%$ with double reading. Single reading + CAD had a significantly higher recall rate $(6.1 \%)$ compared to double reading $(5.0 \%)$.

To conclude, these three studies show partly conflicting results and it is difficult to draw any conclusions. According to Gilbert et al. [71], the two reading methods resulted in equal numbers of cancer cases. However, this was achieved at the expense of a statistically significantly higher recall rate, implying unnecessary additional examinations. Recall rates in the two studies from the USA $[68,69]$ were two to three times higher than in 
Sweden (average 3\% $[20,72]$ ) and not in accordance with European guidelines $(<5 \%[11])$.

\section{Economic aspects}

The results of the literature search on economic aspects show that out of 44 abstracts, only one led to the inclusion of the full-text article [14]. The medical scientific evidence was insufficient to study cost-effectiveness and the quality of the study was judged to be low.

\section{Discussion}

The results of this systematic review indicate that the scientific evidence is insufficient to determine whether single mammographic reading by one breast radiologist $+\mathrm{CAD}$ is as accurate as the current practice of double reading involving two breast radiologists.

CAD has been developed to act as a second reader for two main reasons: to enhance the diagnostic sensitivity of mammography screening and to compensate for the lack of trained breast radiologists. Most of the literature on CAD for mammography comprises studies concerning technical aspects, such as improvements to software, analysis of subtypes of breast cancer, e.g. microcalcifications only, densities only, distortions or combinations of these. The majority of the clinical studies was performed on selected materials enriched with cancer cases, and thus did not represent a true screening situation. Furthermore, comparison with double reading was not a standard procedure in many of the studies. Since the aim of this review was to critically evaluate the scientific evidence of CAD's performance in large populationbased screening programs, only four studies met our strict inclusion criteria [68-71]. Of these, only one was considered to have sufficient relevance and quality [71].

Two major shortcomings in study design apply to all four included studies. One is survival rate, which is the most important outcome in mammography screening. None of these studies compared the survival rates with the two strategies, and therefore the present outcome measures (cancer detection rate and recall rate) can be regarded as surrogate outcomes. The other shortcoming is incomplete follow-up. As pointed out in the study by Gilbert et al. [71], sensitivity will be overestimated because of this shortcoming.

Although the study by Gilbert et al. [71] comprised a large population and had an elaborate study set-up, its generalisability is limited since all participating breast radiologists had extensive experience of mammography screening. This is not always the case in an authentic setting. The impact of CAD performance on scanned analogue radiographs as compared to digital mammography is also a matter of concern.

Initially, all CAD studies were performed on scanned analogue mammograms that were analysed with CAD.
Over time there has been a transition from analogue to digital mammography and this process is still ongoing in many parts of the world. The reliability of CAD analysis of scanned films has been questioned [73]. This aspect, together with the fact that modern mammography is performed in a digital environment, implies that new studies are required to fully understand CAD's performance and outcomes in large population-based screening programmes using digital mammography.

Lack of trained radiologists remains a problem even when CAD is used. Using CAD as a first/second reader due to unavailability of a trained breast radiologist could be unsustainable, for instance due to retirement. In any case, new generations of breast radiologists must be secured. Besides, being able to discuss uncertain cases with an experienced colleague is absolutely essential, both for educational purposes and in order to avoid too many false positives/false negatives. When working with CAD, a single radiologist will always have to make the final decision to recall or not to recall a woman for further work-up. This decision may depend on a single CAD mark in an area where the radiologist did not react initially. In our opinion, the single radiologist using CAD needs to be highly experienced, particularly when deciding not to recall a woman for further work-up when a potential cancer might be missed. In conclusion, education and training of new generations of breast radiologists have to be done irrespective of the use of CAD, although it has been suggested that CAD could be used in the training of radiologists [74].

As pointed out earlier, screening policies vary between countries and this review has been performed from a European perspective. However, all screening settings have some features in common, be they populationbased, centrally-organized or non-organized ("wild" or "opportunistic" screening) mammographies on asymptomatic women. High throughput is one of these factors that place high demands on smooth screening workflows. Integrating CAD into the workflow would mean that the radiologist would have actively to consider all CAD prompts, which in turn increases the total reading time.

High recall rates imply that more women have to return for additional investigation, involving new mammographic images and often also ultrasound examination. In addition, some have to undergo biopsy and in some cases even surgery. This also means more visits to doctors/hospitals for these women. Overall, additional resources are required and women are worried unnecessarily. Since the medical consequences are not convincingly positive, it is not possible to determine either the cost-effectiveness and/or the socioeconomic consequences of replacing one of the readers with CAD in the context of mammography screening. 


\section{Conclusions}

The conclusions from this systematic review are:

- The scientific evidence is insufficient to determine whether $\mathrm{CAD}+$ single reading by one breast radiologist would yield results that are at least equivalent to those obtained in standard practice, i.e. double reading where two breast radiologists independently read the mammographic images.

- Since the medical consequences are uncertain, it is not possible to determine the cost-effectiveness or the socioeconomic consequences of replacing one of the readings with $\mathrm{CAD}$ in the context of mammography screening.

- Since this literature review, CAD technology has advanced further, thanks to improvements in computer software and digitalization.

- Additional prospective and preferably randomized population-based studies are essential to understand the method's specific benefits, consequences, and costs.

\section{Competing interest}

The authors declare that they have no competing interest.

\section{Authors' contributions}

EA: Study concept, analysis, interpretation of data and drafting the manuscript. SZ: Study concept, analysis, interpretation of data and drafting the manuscript. IM: Study concept, analysis, interpretation of data and drafting the manuscript. MHA: Study concept, analysis, interpretation of data and drafting the manuscript. All four authors are responsible for the content and writing of the paper and approved the final manuscript.

\section{Authors' information}

*First authorship shared by Azavedo E and Zackrisson S.

\section{Author details}

'Department of Diagnostic Radiology, Karolinska Institutet, Stockholm, Sweden. ${ }^{2}$ Department of Clinical Sciences in Malmö, Diagnostic Radiology, Lund University, Skåne University Hospital Malmö, Malmö SE-205 02, Sweden. ${ }^{3}$ Swedish Council on Health Technology Assessment (SBU), Stockholm, Sweden. ${ }^{4}$ LIME/MMC, Karolinska Institutet, Stockholm, Sweden.

Received: 20 April 2012 Accepted: 23 June 2012

Published: 24 July 2012

\section{References}

1. Tabar L, Fagerberg CJ, Gad A, Baldetorp L, Holmberg LH, Grontoft O, Ljungquist $U$, Lundstrom B, Manson JC, Eklund G, et al: Reduction in mortality from breast cancer after mass screening with mammography. Randomised trial from the Breast Cancer Screening Working Group of the Swedish National Board of Health and Welfare. Lancet 1985, 1(8433):829-832

2. Andersson I, Aspegren $K$, Janzon L, Landberg T, Lindholm K, Linell F, Ljungberg O, Ranstam J, Sigfusson B: Mammographic screening and mortality from breast cancer: the Malmo mammographic screening trial. BMJ 1988, 297(6654):943-948

3. Bjurstam N, Bjorneld L, Duffy SW, Smith TC, Cahlin E, Eriksson O, Hafstrom $L O$, Lingaas H, Mattsson J, Persson S, et al: The Gothenburg breast screening trial: first results on mortality, incidence, and mode of detection for women ages 39-49 years at randomization. Cancer 1997, 80(11):2091-2099.

4. Frisell J, Glas U, Hellstrom L, Somell A: Randomized mammographic screening for breast cancer in Stockholm. Design, first round results and comparisons. Breast Cancer Res Treat 1986, 8(1):45-54.
5. Vainio H, Bianchini F: IARC Handbooks of Cancer Prevention- Breast Cancer Screening. Lyon, France: IARCPress; 2002:2002.

6. Nystrom L, Andersson I, Bjurstam N, Frisell J, Nordenskjold B, Rutqvist LE: Long-term effects of mammography screening: updated overview of the Swedish randomised trials. Lancet 2002, 359(9310):909-919.

7. Tabar L, Vitak B, Chen TH, Yen AM, Cohen A, Tot T, Chiu SY, Chen SL, Fann JC, Rosell J, et al: Swedish two-county trial: impact of mammographic screening on breast cancer mortality during 3 decades. Radiology 2011, 260(3):658-663.

8. Hellquist BN, Duffy SW, Abdsaleh S, Bjorneld L, Bordas P, Tabar L, Vitak B, Zackrisson S, Nystrom L, Jonsson H: Effectiveness of population-based service screening with mammography for women ages 40 to 49 years: evaluation of the Swedish Mammography Screening in Young Women (SCRY) cohort. Cancer 2011, 117(4):714-722.

9. SOSSEG SOSSEG: Reduction in breast cancer mortality from organized service screening with mammography: 1 . Further confirmation with extended data. Cancer Epidemiol Biomarkers Prev 2006, 15(1):45-51.

10. Gotzsche PC, Nielsen M: Screening for breast cancer with mammography. Cochrane Database Syst Rev 2011, (1):CD001877.

11. Perry N, Broeders M, de Wolf C, Törnberg S, Holland R, von Karsa L: European guidelines for quality assurance in breast cancer screening and diagnosis. 4th edition. Luxembourg: Office for Official Publications of the European Communities; 2006. ISBN 2006 ISBN 92-79-01258-4: EU.

12. Helvie M: Improving mammographic interpretation: double reading and computer-aided diagnosis. Radiol Clin North Am 2007, 45(5):801-811. vi.

13. Guerriero C, Gillan MG, Cairns J, Wallis MG, Gilbert FJ: Is computer aided detection (CAD) cost effective in screening mammography? A model based on the CADET II study. BMC Health Serv Res 2011, 11(1):11.

14. Taylor P, Champness J, Given-Wilson R, Johnston K, Potts H: Impact of computer-aided detection prompts on the sensitivity and specificity of screening mammography. Health Technol Assess 2005, 9(6):1-58. iii.

15. Houssami N, Given-Wilson R: Incorporating new technologies into clinical practice without evidence of effectiveness in prospective studies: computer-aided detection (CAD) in breast screening reinforces the need for better initial evaluation. Breast 2007, 16(3):219-221

16. Houssami N, Given-Wilson R, Ciatto S: Early detection of breast cancer: overview of the evidence on computer-aided detection in mammography screening. J Med Imaging Radiat Oncol 2009, 53(2):171-176.

17. Taylor P, Potts HW: Computer aids and human second reading as interventions in screening mammography: two systematic reviews to compare effects on cancer detection and recall rate. Eur J Cancer 2008, 44(6):798-807.

18. Bennett RL, Blanks RG, Moss SM: Does the accuracy of single reading with CAD (computer-aided detection) compare with that of double reading?: A review of the literature. Clin Radiol 2006, 61(12):1023-1028.

19. SBU: Computer-Aided Detection (CAD) in Mammography Screening. Stockholm: Statens beredning för medicinsk utvärdering (SBU): SBU; 2011.

20. Azavedo E, Svane G: Radiologic aspects of breast cancers detected through a breast cancer screening program. Eur J Radiol 1991 13(2):88-90.

21. Whiting P, Rutjes AW, Reitsma JB, Bossuyt PM, Kleijnen J: The development of QUADAS: a tool for the quality assessment of studies of diagnostic accuracy included in systematic reviews. BMC Med Res Methodol 2003, $3: 25$.

22. Guyatt $G H$, Oxman AD, Vist GE, Kunz R, Falck-Ytter Y, Alonso-Coello P, Schunemann HJ: GRADE: an emerging consensus on rating quality of evidence and strength of recommendations. BMJ 2008, 336(7650):924-926.

23. Schunemann HJ, Oxman AD, Brozek J, Glasziou P, Bossuyt P, Chang S, Mut $P$, Jaeschke R, Guyatt GH: GRADE: assessing the quality of evidence for diagnostic recommendations. Evid Based Med 2008, 13(6):162-163

24. Boyer B, Balleyquier C, Granat O, Pharaboz C: CAD in questions/answers Review of the literature. Eur J Radiol 2009, 69(1):24-33.

25. G-S G, Chersevani R, Ciatto S, Del Favero C, Frigerio A, Giordano L, Giuseppetti G, Naldoni C, Panizza P, Petrella M, Gruppo di studio G-S, Chersevani R, Ciatto S, Del Favero C, Frigerio A, Giordano L, Giuseppetti G, Naldoni C, Panizza P, Petrella M, et al: "CADEAT": considerations on the use of CAD (computer-aided diagnosis) in mammography. La Radiologia medica 2010, 115(4):563-570 
26. Kolb GR: The financial impact of computer-aided detection on the mammography practice. Applied Radiology 2001, 30(11 SUPPL.):21-24.

27. Nishikawa RM: Evaluation of computer-aided detection and computer detection systems. Applied Radiology 2001, 30(11 SUPPL.):14-16.

28. Noble M, Bruening W, Uhl S, Schoelles K: Computer-aided detection mammography for breast cancer screening: systematic review and meta-analysis. Arch Gynecol Obstet 2009, 279(6):881-890.

29. Cawson JN, Nickson C, Amos A, Hill G, Whan AB, Kavanagh AM: Invasive breast cancers detected by screening mammography: a detailed comparison of computer-aided detection-assisted single reading and double reading. J Med Imaging Radiat Oncol 2009, 53(5):442-449.

30. van den Biggelaar FJ, Kessels AG, van Engelshoven JM, Flobbe K: Strategies for digital mammography interpretation in a clinical patient population. Int J Cancer 2009, 125(12):2923-2929.

31. Paquerault S, Samuelson FW, Petrick N, Myers KJ, Smith RC: Investigation of reading mode and relative sensitivity as factors that influence reader performance when using computer-aided detection software. Acad Radiol 2009, 16(9):1095-1107.

32. van den Biggelaar FJ, Kessels AG, van Engelshoven JM, Boetes C, Flobbe K: Computer-aided detection in full-field digital mammography in a clinical population: performance of radiologist and technologists. Breast Cancer Res Treat 2010, 120(2):499-506.

33. James JJ, Cornford EJ: Does computer-aided detection have a role in the arbitration of discordant double-reading opinions in a breast-screening programme? Clin Radiol 2009, 64(1):46-51.

34. Kim SJ, Moon WK, Cho N, Cha JH, Kim SM, Im JG: Computer-aided detection in full-field digital mammography: sensitivity and reproducibility in serial examinations. Radiology 2008, 246(1):71-80.

35. Brancato B, Houssami N, Francesca D, Bianchi S, Risso G, Catarzi S, Taschini R, Rosselli Del Turco M, Ciatto S: Does computer-aided detection (CAD) contribute to the performance of digital mammography in a selfreferred population? Breast Cancer Res Treat 2008, 111(2):373-376.

36. Yang SK, Moon WK, Cho N, Park JS, Cha JH, Kim SM, Kim SJ, Im JG: Screening mammography-detected cancers: sensitivity of a computeraided detection system applied to full-field digital mammograms. Radiology 2007, 244(1):104-111.

37. Skaane P, Kshirsagar A, Stapleton S, Young K, Castellino RA: Effect of computer-aided detection on independent double reading of paired screen-film and full-field digital screening mammograms. AJR Am J Roentgenol 2007, 188(2):377-384.

38. Gilbert FJ, Astley SM, McGee MA, Gillan MG, Boggis CR, Griffiths PM, Duffy SW: Single reading with computer-aided detection and double reading of screening mammograms in the United Kingdom National Breast Screening Program. Radiology 2006, 241(1):47-53.

39. Dean JC, Ilvento CC: Improved cancer detection using computer-aided detection with diagnostic and screening mammography: prospective study of 104 cancers. AJR Am J Roentgenol 2006, 187(1):20-28.

40. Hukkinen $K$, Vehmas T, Pamilo M, Kivisaari L: Effect of computer-aided detection on mammographic performance: experimental study on readers with different levels of experience. Acta Radiol 2006, 47(3):257-263.

41. Ciatto S, Ambrogetti D, Collini G, Cruciani A, Ercolini E, Risso G, Rosselli Del Turco M: Computer-aided detection (CAD) of cancers detected on double reading by one reader only. Breast 2006, 15(4):528-532.

42. Hukkinen $\mathrm{K}$, Pamilo $\mathrm{M}$ : Does computer-aided detection assist in the early detection of breast cancer? Acta Radiol 2005, 46(2):135-139.

43. Destounis SV, DiNitto P, Logan-Young W, Bonaccio E, Zuley ML, Willison KM: Can computer-aided detection with double reading of screening mammograms help decrease the false-negative rate? Initial experience. Radiology 2004, 232(2):578-584.

44. Ciatto S, Rosselli Del Turco M, Burke P, Visioli C, Paci E, Zappa M: Comparison of standard and double reading and computer-aided detection (CAD) of interval cancers at prior negative screening mammograms: blind review. Br J Cancer 2003, 89(9):1645-1649.

45. Ciatto S, Brancato B, Rosselli Del Turco M, Risso G, Catarzi S, Morrone D, Bricolo D, Zappa M: Comparison of standard reading and computer aided diagnosis (CAD) on a proficiency test of screening mammography. Radiol Med 2003, 106(1-2):59-65.

46. Brem RF, Baum J, Lechner M, Kaplan S, Souders S, Naul LG, Hoffmeister $\mathrm{J}$ : Improvement in sensitivity of screening mammography with computer-aided detection: a multiinstitutional trial. AJR Am J Roentgenol 2003, 181(3):687-693.

47. Quek ST, Thng CH, Khoo JB, Koh WL: Radiologists' detection of mammographic abnormalities with and without a computer-aided detection system. Australas Radiol 2003, 47(3):257-260

48. Zheng B, Hardesty LA, Poller WR, Sumkin JH, Golla S: Mammography with computer-aided detection: reproducibility assessment initial experience. Radiology 2003, 228(1):58-62

49. Karssemeijer N, Otten JD, Verbeek AL, Groenewoud JH, de Koning HJ, Hendriks JH, Holland R: Computer-aided detection versus independent double reading of masses on mammograms. Radiology 2003, 227(1):192-200.

50. Ciatto S, Del Turco MR, Risso G, Catarzi S, Bonardi R, Viterbo V, Gnutti P, Guglielmoni B, Pinelli L, Pandiscia A, et al: Comparison of standard reading and computer aided detection (CAD) on a national proficiency test of screening mammography. Eur J Radiol 2003, 45(2):135-138.

51. Malich A, Marx C, Facius M, Boehm T, Fleck M, Kaiser WA: Tumour detection rate of a new commercially available computer-aided detection system. Eur Radio/ 2001, 11(12):2454-2459.

52. Moberg K, Bjurstam N, Wilczek B, Rostgard L, Egge E, Muren C: Computed assisted detection of interval breast cancers. Eur J Radiol 2001, 39(2):104-110

53. Warren Burhenne $L$, Wood SA, D'Orsi CJ, Feig SA, Kopans DB, O'Shaughnessy KF, Sickles EA, Tabar L, Vyborny CJ, Castellino RA: Potential contribution of computer-aided detection to the sensitivity of screening mammography. Radiology 2000, 215(2):554-562.

54. Jiang Y, Nishikawa RM, Schmidt RA, Metz CE, Giger ML, Doi K: Improving breast cancer diagnosis with computer-aided diagnosis. Acad Radiol 1999, 6(1):22-33.

55. Thurfjell E, Thurfjell MG, Egge E, Bjurstam N: Sensitivity and specificity of computer-assisted breast cancer detection in mammography screening. Acta Radiol 1998, 39(4):384-388.

56. Sang KY, Woo KM, Cho N, Jeong SP, Joo HC, Sun MK, Seung JK, Im JG: Screening mammography-detected cancers: Sensitivity of a computeraided detection system applied to full-field digital mammograms. Radiology 2007, 244(1):104-111.

57. Li JG, Li S, Xu HM, Xu K: Evaluation on the use and results of computeraided detection for full-field digital mammorgraphy. Chinese Journal of Radiology 2006, 40(7):729-732.

58. Birdwell RL, Bandodkar P, Ikeda DM: Computer-aided detection with screening mammography in a university hospital setting. Radiology 2005, 236(2):451-457.

59. Cupples TE, Cunningham JE, Reynolds JC: Impact of computer-aided detection in a regional screening mammography program. AJR Am J Roentgenol 2005, 185(4):944-950.

60. Fenton JJ, Taplin SH, Carney PA, Abraham L, Sickles EA, D'Orsi C, Berns EA, Cutter G, Hendrick RE, Barlow WE, et al: Influence of computer-aided detection on performance of screening mammography. N Engl J Med 2007, 356(14):1399-1409.

61. Freer TW, Ulissey MJ: Screening mammography with computer-aided detection: prospective study of 12,860 patients in a community breast center. Radiology 2001, 220(3):781-786.

62. Gur D, Sumkin JH, Rockette HE, Ganott M, Hakim C, Hardesty L, Poller WR, Shah R, Wallace L: Changes in breast cancer detection and mammography recall rates after the introduction of a computer-aided detection system. J Nat/ Cancer Inst 2004, 96(3):185-190.

63. Karssemeijer N, Bluekens AM, Beijerinck D, Deurenberg JJ, Beekman M, Visser R, van Engen R, Bartels-Kortland A, Broeders MJ: Breast cancer screening results 5 years after introduction of digital mammography in a population-based screening program. Radiology 2009, 253(2):353-358.

64. Ko JM, Nicholas MJ, Mendel JB, Slanetz PJ: Prospective assessment of computer-aided detection in interpretation of screening mammography. AJR Am J Roentgenol 2006, 187(6):1483-1491.

65. Morton MJ, Whaley DH, Brandt KR, Amrami KK: Screening mammograms: interpretation with computer-aided detection-prospective evaluation. Radiology 2006, 239(2):375-383.

66. Sanchez Gomez S, Torres Tabanera M, Vega Bolivar A, Sainz Miranda M, Baroja Mazo A, Ruiz Diaz M, Martinez Miravete P, Lag Asturiano E, Munoz Cacho P, Delgado Macias T: Impact of a CAD system in a screen-film mammography screening program: A prospective study. Eur J Radiol 2010 , 
67. James JJ, Gilbert FJ, Wallis MG, Gillan MG, Astley SM, Boggis CR, Agbaje OF, Brentnall AR, Duffy SW: Mammographic features of breast cancers at single reading with computer-aided detection and at double reading in a large multicenter prospective trial of computer-aided detection: CADET II. Radiology 2010, 256(2):379-386.

68. Georgian-Smith D, Moore RH, Halpern E, Yeh ED, Rafferty EA, D'Alessandro HA, Staffa M, Hall DA, McCarthy KA, Kopans DB: Blinded comparison of computer-aided detection with human second reading in screening mammography. AJR Am J Roentgenol 2007, 189(5):1135-1141.

69. Gromet M: Comparison of computer-aided detection to double reading of screening mammograms: review of 231,221 mammograms. AJR Am J Roentgenol 2008, 190(4):854-859.

70. Khoo LA, Taylor P, Given-Wilson RM: Computer-aided detection in the United Kingdom National Breast Screening Programme: prospective study. Radiology 2005, 237(2):444-449.

71. Gilbert FJ, Astley SM, Gillan MG, Agbaje OF, Wallis MG, James J, Boggis CR, Duffy SW: Single reading with computer-aided detection for screening mammography. N Engl J Med 2008, 359(16):1675-1684.

72. Azavedo E, Svane G: Radial scars detected mammographically in a breast cancer screening programme. Eur J Radiol 1992, 15(1):18-21.

73. Malich A, Azhari T, Bohm T, Fleck M, Kaiser WA: Reproducibility-an important factor determining the quality of computer-aided detection (CAD) systems. Eur J Radiol 2000, 36(3):170-174.

74. Luo P, Qian W, Romilly P: CAD-aided mammogram training. Acad Radiol 2005, 12(8):1039-1048.

doi:10.1186/1471-2342-12-22

Cite this article as: Azavedo et al: Is single reading with computer-aided detection (CAD) as good as double reading in mammography screening? A systematic review. BMC Medical Imaging $201212 \cdot 22$

\section{Submit your next manuscript to BioMed Central and take full advantage of:}

- Convenient online submission

- Thorough peer review

- No space constraints or color figure charges

- Immediate publication on acceptance

- Inclusion in PubMed, CAS, Scopus and Google Scholar

- Research which is freely available for redistribution 